\title{
NOTAS SOBRE EL IMPERATIVO DEL VERBO ESPAÑOL
}

\author{
Gaudioso Gimenez Resano *
}

1. El término "imperativo" se autodefine semánticamente. Es obvio que el español se sirve de otros procedimientos - aparte de la propia forma verbal- para expresar un mandato. Son usos que facilitan muy ricas y variadas construcciones, y que han de quedar -por la razón que dicta el título del presente trabajo- fuera del objeto inmediato de lo que me propongo estudiar aquí. Por lo demás, tampoco el imperativo indica siempre una orden estricta. En ocasiones desliza su significado - contando con la significación de contexto- hacia lo que bien pudiera ser una invitación complaciente, un permiso amable, como advertimos en Entra, entra, no tengas vergüenza o Cógelo, anda, cógelo, como si fuera tuyo. Lo empleamos para recabar la atención de nuestro interlocutor, dirigir el ejercicio de su entendimiento, voluntad o sentidos hacia referencias conocidas o desconocidas, pasadas o futuras: Mira, ponte en mi lugar y escúchame. Vea, vea lo que ha conseguido con sus reproches. Vea lo que se nos viene encima, y todo por decir la verdad.

Mandar y obedecer (o no) dependen de un proceso interior que enfrenta las voluntades de dos sujetos. Esta función conativa del lenguaje - por la que intentamos influir sobre los demás- es de suma transcendencia en el desarrollo de la convivencia humana. Los lingüistas la han destacado en los últimos tiempos y han tenido que rozar el terreno de la psicología y de la sociología. Es natural que nosotros acotemos ahora el campo y lo reduzcamos a la parcela puramente lingüística.

El imperativo se aparta de las otras formas finitas de la conjugación - pero no hasta el extremo de quedar fuera de la estructura verbal- por ofrecer rasgos propios en lo tocante a las categorías que regulan la sistemática del verbo español, ya en el plano morfológico, y debido también a su peculiaridad semántica, donde se mezcla lo informativo y lo apelativo. Trataré, en estas páginas, de precisar su lugar dentro del verbo, y me ocuparé sobre todo de las cuestiones más controvertidas. Como hay otros que las han abordado, será menester que revisemos algunos puntos, aceptando o rechazando interpretaciones y solucio-

* Universidad de Zaragoza. 
nes habidas en lo general y en lo particular, de camino hacia las nuestras propias.

2. Las categorías verbales que comporta el imperativo confluyen en su estructura morfológica ${ }^{1}$ y se manifiestan a través de ella. Hoy por hoy, no existe un acuerdo común sobre cuáles sean ni, luego, acerca del alcance de su comportamiento. Tantas y tan intrincadas dificultades han dado paso a teorías, posiciones y planteamientos distintos, incluso dispares.

2.1. La persona y el número cifran el componente formal primario y de base. El número opone la no-pluralidad a la pluralidad, marcada ésta, en el imperativo, por la - $d$ final, que opera, por lo tanto, como un morfema distintivo. Persona + número componen una entidad inseparable, pues la designación numérica no recae en el verbo sobre la sustancia de significado, como ocurre en el nombre, sino en el sujeto del predicado, cuya referencia deíctica está determinada por un sistema pronominal de personas gramaticales. En el imperativo, se conectan los dos sujetos que intervienen en el acto de mandar: el sujeto del mandato y el sujeto de lo mandado. El primero activa el ejercicio de su voluntad ordenante $\mathrm{y}$, hecha lenguaje, él mismo la transmite y formula, por lo que se convierte a la vez en el sujeto de la declaración imperativa. Pero el mandato incluye también aquello que se manda, y constituye la materia semántica del verbo. Va dirigido a otra persona, que es el sujeto real del predicado, pues ella es quien, en definitiva, decide su cumplimiento o no, lo deja en suspenso o lo resuelve en actuación. $Y$, puesto que una orden ha de transmitirse directamente y exige que alguien la reciba (de lo contrario - lo veremos luego-, no se trata de un mandato auténtico), el imperativo pone en juego un sistema de incidencias recíprocas: las personas gramaticales

1 La morfología se reduce a los formantes de la segunda persona: / -a, canta /, /-e, coge /, / o cero, ven /; en el sigunlar, y /,-d, cantad, coged, venid /, en el plural.

La - $d$ podía escribirse - $t$ en la lengua antigua (andat, sabet). Llegó a perderse en la pronunciación. Fenómeno que estuvo de moda entre los clásicos (andá, sabé, subî). Todavía el maestro Correas (Arte de la lengua española castellana, ed. y pról. de E. Alarcos García) recoge las formas en vocal acentuada -sin -d final-, como paradigma de las formas imperativas, junto con las que la llevan. Hoy desaparece delante del enclítico os, amaos (excepto en el verbo ir, idos). Dialectalmente se conservó la -e final en leonés (dade, salide). Forma que existió en castellano primitivo, de donde derivan dai, facei, sali, vulgares en ciertas partes de Castilla y muy frecuentes en leonés, gallego y portugués (vid. R. Menéndez Pidal, Manual de Gramática Histórica Española, Madrid, 1958, pág. 281). Era frecuente también la anteposición de la $l$ del pronombre enclítico a la $-d$ final: *miralde por miradle. 
NOTAS SOBRE EL IMPERATIVO DEL VERBO ESPAÑOL

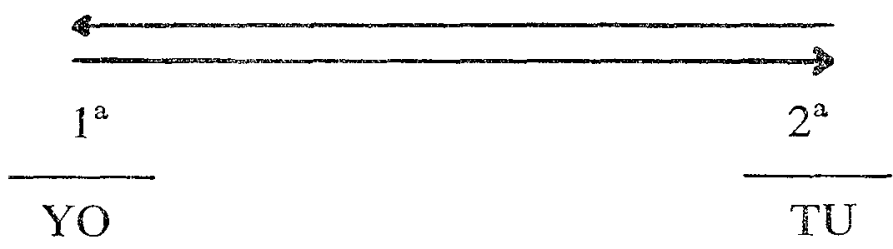

(o formalmente la $3^{\mathrm{a}}$ en el tratamiento de cortesía, "usted", "ustedes", pero cuya referencia es la $2^{\mathrm{a}}$ persona)

que, en el proceso scmasiológico y onomasiológico de la comunicación, representan al

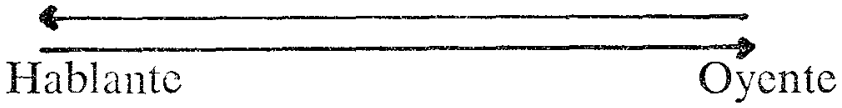

y en la transmisión imperativa

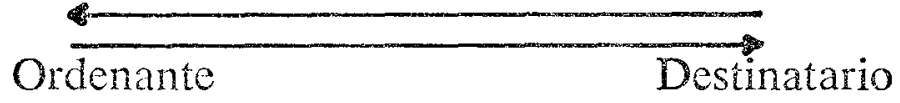

2.2. El problema capital -foco de las polémicas que suscita el imperativo - es si cabe definirlo como un modo del verbo. Se han dado respuestas muy diferentes, aun contrarias: desde la afirmativa, admitiendo su independencia modal, hasta la negativa, que lo inserta dentro del subjuntivo, o bien la que le niega dicha categoría. La cuestión debe ser planteada, sin duda, desde la definición del modo -asunto nada fácil y hartamente discutido por los gramáticos-, que unas veces se ha orientado bajo una perspectiva sintáctico-funcional, y otras, las más, nocional, en cuanto a la actitud que toma el hablante en orden a los hechos que enuncia y - no lo olvidemos - en consideración al oyente. Criterio este que va unido al de la capacidad que tiene para manifestar las modalidades, es decir, para desarrollar las funciones del lenguaje. Hay que advertir que el supuesto conceptual se refleja en la sintaxis, porque la actitud mental se conforma y configura en el verbo y se acoge así a todos los condicionamientos del sintagma predicativo. Aunque queda muy lejos de nuestro propósito entrar ahora en la discusión, adelanto mi opinión de que ambos criterios pueden coexistir y no veo motivo para desligarlos de antemano, mucho menos para enfrentarlos a costa de prescindir de las consecuencias que se derivan de alguno de ellos.

2.2.1. La modalidad es una manifestación aspectual que caracteriza e ilumina la frase, pero proyectada por la luz que arroja el modo, y no al revés. Huelga decir que no estoy conforme con la tesis de $\mathrm{A}$. García Calvo acerca de la "modalidad de la frase", propuesta como un intento de superar la categoría "modo" en su sentido tradicional, ${ }^{2}$ y

2 A. García Calvo, "Preparación a un estudio orgánico de los modos verbales sobre el ejemplo del verbo antiguo", en Emerita, XXVIII, 1960, págs. 1-47. Principalmente: "Funciones del lenguaje y modalidades de la frase", en Estudios Clásicos, 4, págs. 329-350.

Vid. también, al respecto, las correcciones a la doctrina tradicional hecha por L. Rubio, "Los modos verbales latinos", en Emerita, XXXV, 1968, págs. 449-486. 
corroborada con fervor por el profesor S. Mariner. ${ }^{3}$ Mi discrepancia se hace más notable todavía cuando ni siquiera pienso que el imperativo sea una simple "modalidad" del subjuntivo.

La modalidad de la frase no erosiona los fundamentos del modo ni en cuanto al criterio de la actitud mental - ya mantenida por los gramáticos clásicos-, ni tampoco respecto al principio determinante de la "influencia o régimen de una palabra a que el verbo esté o pueda estar subordinado", según la definición de A. Bello. S. Mariner se opone al maestro venezolano por su unitarismo, y destaca el aspecto plurivalente en la concepción del modo verbal. Cree que, dada la posibilidad de indagar, junto a la "actitud", el papel que en el funcionamiento de la categoría modal tiene la inflexión por dependencia contextual, de la misma manera "se podría encontrar una invitación a investigar el que corresponda a la modalidad de la frase en la existencia misma de unas formas modales definidas y rotuladas de acuerdo con uno de los tipos de dicha modalidad". 4

Mas, por mucho empeño que pusiéramos, nos sería muy difícil cumplir con tal invitación. En primer lugar, porque a una modalidad de frase no le está reservada una misma y única función; y, entonces, ¿por cuál de ellas habríamos de definirla, si se obtienen distintos tipos de modo? De esta suerte, considerando el lenguaje como "expresivo" e "impre-

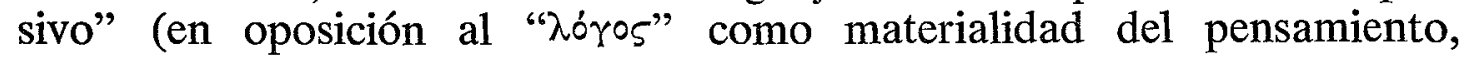
según quiere García Calvo), y tratásemos de conseguir de la función impresiva un criterio externo de clasificación de la frase, nos veríamos en la necesidad de aunar las varias opciones posibles en la clave común de la función impresiva, por cuanto el hablante intenta lograr fundamentalmente tres cosas — señaladas por García Calvo-: 1) acción (modalidad "yusiva"), 2) respuesta (modalidad "interrogativa"), 3) conocimiento o modificación del pensamiento (modalidad "declarativa"), a pesar de que cada una provoca reacciones distintas en el oyente, y forzaría a distinguir, en un determinado tipo de frase, otros "subtipos", otras "submodalidades", ante un despliegue incesante de posibilidades nuevas. Hemos de contar también con que los factores que tipifican y caracterizan la modalidad de la frase son de muy distinta naturaleza que los que arguyen la categoría modo en las formas verbales. No se eliminan entre sí, pero tampoco se confunden. En la frase, la modalidad - y no el modo que le da vida - se revela primordialmente por rasgos suprasegmentales. Vemos, así, que sólo una entonación adecuada podrá aclararnos la intención conativa o sencillamente declarativa entre: Ana, pinta el tejado con colores rojos y Ana pinta el tejado con colores rojos, confirmada por la pausa o por una secuencia de entonación ininterrumpida,

\footnotetext{
3 "Triple noción básica en la categoría modal castellana", RFE, Julio-Diciembre, 1971, págs. 209-252. Trabajo que completa una trayectoria recogida en "Estructura de la categoría verbal 'modo' en latín clásico", Emerita, XXV, 1957, págs. 449-486; y "Noción básica de los modos en el estilo indirecto latino", Emerita, XXXIII, págs. $47-59$.
}

${ }_{4}$ Triple noción, supra, 214. 
respectivamente. De igual manera, entre: Ana pinta el tejado con colores rojos y ¿Ana pinta el tejado con colores rojos?, la anticadencia característica será la que establezca la modificación interrogativa. Es evidente que se trata de modalidades distintas. Pero son, en parte, las mismas que se dan, p. e., entre: La maestra DICE que Ana PINTA el tejado con colores rojos y ¿La maestra QUIERE que Ana PINTE el tejado con colores rojos? Esto es, que el hablante informe o pregunte acerca de la disposición de "la maestra" respecto al hecho de que "Ana pinte el tejado", y al color, comporta, en efecto, un distinto tipo de modalidad de la frase. Ahora bien, está muy claro que no es la condición interrogativa la que determina el subjuntivo (porque podemos decir: ¿La maestra dice que Ana PINTA el tejado con colores rojos?), sino que se debe a la manera como el que habla encara los hechos del predicado, ante la actitud de "la maestra", confirmada por las significaciones de los verbos "decir" y "querer". Son precisamente estos factores los que colocan la etiqueta de modo al verbo. Y la modalidad de la frase no lo desplaza porque son dos realidades distintas y con distinto comportamiento. Así pues, prevalece, para mí, la categoría modo en el imperativo —según el compromiso que adquiere como forma verbal que es-, y no parto de la frase, es decir, de la modalidad imperativa que la envuelve.

2.2.2. Aunque sin apoyos teóricos - y un tanto a la ligerala verdad es que nuestras Gramáticas suelen dejar aparte al imperativo como un modo independiente (sin contar con quienes no le reconocen dicha categoría). Los gramáticos antiguos así lo definieron en base a su etimología, como un adjetivo verbal que ha quedado, por elipsis del sustantivo, de la expresión "modus imperativus", al igual que "indicativo" y "subjuntivo". Pero no faltan los que lo reducen a alguno de estos dos en virtud de ciertas conexiones nocionales y morfofuncionales. Sobre todo se le ha emparentado con el subjuntivo. ${ }^{5}$ Bello distingue las formas optativas, o del Modo optativo, dentro del subjuntivo común: las que "se emplean en proposiciones independientes para significar el deseo de un hecho positivo o negativo". Las formas optativas se llaman "imperativas", y toman una inflexión especial "cuando la persona a quien hablamos es la que debe cumplir el deseo, y lo que se desea se supone depender de su voluntad, y se expresa por una proposición que no contiene palabras negativas". "Para César Hernández, las formas del imperativo (canta, cantad) vienen a ser alomorfos de las formas subjuntivas; es decir, que "el originario imperativo, sin un morfo de categoría, única forma de lo que fue un tiempo-modo, es en el sistema actual de la lengua una variante del subjuntivo", de tal manera que "no puede interpretarse como

5 F. Sato ("Valeur modale du sobjonctif en français contemporain", Le français moderne, 41, 1973, pp. 39-41), sin embargo, lo relaciona con el indicativo, en el plano de la afectividad, mientras que subjuntivo-infinitivo describen el plano de lo absoluto y general. pág. 178.

6 A. Bello, Gramática de la lengua castellana, Buenos Aires, Sopena, 1973, 
modo particular. Se trata de una forma exclusivamente de la segunda persona, de la elocución directa con función apelativa o inyuntiva".? Asimismo, Martín S. Ruipérez cree que "subjuntivo e imperativo se conducen como una sola unidad" frente al indicativo. Propone como prueba la conmutabilidad en posiciones de plena diferenciación, y concluye que "no hay ninguna posición contextual en que sea posible la conmutación entre imperativo y subjuntivo". Así, las formas del imperativo sólo aparecen en uso independiente para expresar una orden: canta, cantad, y no son conmutables por las del subjuntivo, cantes, cantéis, cuyo uso independiente es imposible. Sin embargo, pueden ser conmutadas por las de indicativo, cantas, cantáis. $^{8}$ Con ser verdad -aunque, por otra parte, su mismo argumento puede volverse contra lo que pretende probar, ya que, desde la perspectiva de una "mínima diferenciación, imperativo e indicativo se sitúan frente al subjuntivo por su independencia-, esta manera de desatar el nudo gordiano del problema me parece insuficiente y simplista por atenerse sólo a una apreciación unidimensional. Otros hilos lo enmarañan además del de la conmutabilidad, que es un hecho de construcción. Sin duda, la vinculación -o apartamiento- del imperativo con los otros modos del verbo implica unas relaciones más internas.

2.2.3. Insisto - porque encamina mi punto de vista_ en que el proceso que desarrolla el acto de mandar gira en torno a la persona locutiva (YO) y la terminal alocutiva directa (TU, VOSOTROS). Ya vimos que la estructura más antigua muestra que el imperativo se ha restringido a la segunda persona y se ha fundado siempre sobre ella. Pero se ha reducido a instancia de su propia naturaleza y no por préstamos gratuitos. Es justo afirmar, pues, que el subjuntivo no ha venido a llenar ninguna plaza vacante en el paradigma del imperativo, ni por la forma, ni por la significación o la función. Contra lo habitual, creo que es inexacto presentar las formas subjuntivas (extraídas del presente) como sustitutas del imperativo - ante la supuesta falta de formas propiaspara las personas primera plural y tercera, singular y plural. Realmente, tales personas tienen muy poco que ver con el imperativo, con la autenticidad del mandato que infiere, al menos en su acepción genuina - que es la única válida por definición-. ${ }^{9}$ Quedan fuera del circuito de la

${ }^{7}$ C. Hernández, "Sobre el tiempo en el verbo español", en Revista Española de Lingüística, 3.1, 1973, págs. 143-178.

${ }_{8}$ Martín S. Ruipérez, "Notas sobre estructura del verbo español" (en Problemas y principios del estructuralismo lingüístico, Madrid, CSIC, 1967, pág. 93).

9 Recordemos que el latín enriqueció el paradigma de su imperativo -del que el castellano es un heredero fiel-, seguramente como consecuencia de la analogía con los otros modos. De esta manera especificó formas para la distinción de personas (y de voces). Si las del tema puro - sin vocal temática en unos verbos, o con ella en otros- quedaron para la segunda persona de singular, el plural, en cambio, siguió el esquema del indoeuropeo, que utilizaba una forma inyuntiva (v. gr.: bhere-te, de donde gr. $\varphi \varepsilon p \varepsilon \tau \varepsilon$, sansc. bhara-ta). Estructura idéntica a la de los imperativos latinos como agite, legete. Las otras personas estaban marcadas por otras características en un llamado "imperativo futuro", con el sufijo to -tod, de base no verbal, el último, procedente del abl. del pron. so o tod. 
intercomunicación necesaria, fuera del espacio físico -mental al que el hablante pueda acceder, y de ningún modo se hacen destinatarias de la elocución yusiva. En la medida en que no está presente el destinatario, o se difumina el contorno de su figura individualizada, concreta, para esconderse en una colectividad genérica, disminuyen la intensidad y la eficacia del mandato y esas otras personas se acogen, entonces, a la amplia onda de expansión de las acepciones del subjuntivo, modo que, en lo tocante a la significación yusiva, nunca expresa un mandamiento absoluto y tajante. Por lo mismo, la tercera persona (excluido el tratamiento cortés, claro está) denota el deseo del hablante. Nada más. El sentido que se desprende, p. e., de Recoja Tomás las armas de sus compañeros o Barra ella su habitación no alcanza normalmente (el adverbio me sirve para eludir aquellas interpretaciones modificadas por una situación de contexto, esto es, con una clara modificación del modo natural de entender, como si la autoridad reconocida de quien pronuncia las frases convirtiera sus deseos en ley de mandato, caso, aquí, del Capitán respecto a un subordinado o la Superiora respecto a alguien de la Comunidad que dirige), no alcanza - digo- más que a la modalidad desiderativa (no imperativa), por cuanto el hablante manifiesta sólo lo que es deseable para él. Quizá tenga el ánimo de obligar (a que Tomás recoja las armas o a que Ella barra su habitación), pero su intención no resultará actualizada en una orden, no podrá pasar a constituir un verdadero mandato mientras exista la distancia que impida la comunicación directa, que la orden llegue a su destino. Es inútil, si desde el principio se sabe ineficaz. Será necesario, en todo caso, que un tercero advierta (a Tomás o a Ella) que otro tiene la voluntad de someterles a dicha obligación. Y ello porque la intención conativa no pudo recorrer por entero el camino que terminara en el mandato. La primera persona plural permite avanzar un poco más, pero tampoco llegar al final del recorrido. Hay aquí, al menos, un oyente capaz de recibir el mensaje imperativo, pero mezclado con el Yo-Hablante, quien se hace parte del interlocutor. El que habla es a la vez sujeto activo (emisor) y pasivo (receptor) de su propio mandato. $Y$, en virtud de que uno no se manda a sí mismo, el mandato pierde autenticidad y valor y deriva -consecuencia de ese coprotagonismo- en un ruego más o menos vehemente, en una invitación más o menos apremiante, incluso - pero no más allá - en una exhortación a que los demás, sus interlocutores, realicen algo juntamente con él, coparticipen en la misma empresa. La primera y la tercera persona son portadoras de una idea no cabalmente impera-

(V.E. Hernández Vista ha puesto en entredicho el origen indoeuropeo de las formas en -to en un trabajo póstumo: "Estructura temporal del modo de la actuación. Presente y futuro de imperativo", REL, 6.2, 1976, págs. 253-268). Y llegamos así a lo que importa para nuestra tesis: a reconocer -con el profesor Bassols, a quien hemos seguido en la presente nota (vid. Sintaxis latina, Madrid, CSIC, 1963)- en aquellas otras personas una atenuación de la fuerza del mandato y una liberación del rigor de la urgencia e inmediatez de la acción. 


\section{Gaudioso Giménez Resano}

tiva y van enmarcadas en el ancho contorno de las modalidades del subjuntivo.

También la prohibición está relacionada con estos matices del subjuntivo. Aunque No corras supone un mandato tan categórico como Corre, entre la afirmación y la negación asoman, sin embargo, las connotaciones que acusan sus diferencias y explican el origen de la construcción prohibitiva, revelada en latín por los mismos motivos. No corras arguye una disposición manifiesta, una determinación firme a actuar, o una acción ya iniciada tal vez. La prohibición obliga nada menos que a desistir de un propósito o suspender lo que se está realizando. No es extraño, pues, que adopte entonces un cierto tono de cortesía, de ruego, acorde con la orientación desiderativa-exhortativa que solamente el subjuntivo es capaz de denotar.

Por tanto, no hay, en legítima propiedad, más imperativo que el de segunda persona. ${ }^{10}$

Respecto a su comportamiento en la estructura que tejen los modos verbales, se aparta del indicativo y del subjuntivo porque se opone a ellos, y tal oposición corrobora su autoctonía modal, implícita en la forma y confirmada por el contenido. Del primero, porque éste sitúa el enunciado fuera de la perspectiva mental o anímica de quien lo emite. No se trata de una "objetivación" — pues supondría el resultado de un proceso de transformación inicial por parte del hablante-, sino de "objetividad" como trasunto de la realidad misma patente en el predicado. En efecto, si yo digo que Elvira limpia su bolso, me limito a informar acerca de lo que Elvira hace. No intervengo para nada en la creación de esta realidad. Mientras que el imperativo implica una cierta subjetivación al emerger el predicado del ámbito de mi voluntad. Depende de mí. Elvira, limpia tu bolso, esto es, porque "yo lo quiero", porque "yo lo mando". Se trata, sí, de una enunciación proyectada y dirigida por la intencionalidad del hablante. Pero no llega a confundirse con el subjuntivo. No, desde luego, con la modalidad optativa que sólo declara el deseo del hablante y no busca influir sobre la otra persona, al menos en dirección recta. Es obvio que la frase: Quiero que Elvira limpie su bolso no ejerce la función conativa - que va directamente al oyente_ de Elvira, limpia tu bolso. Para relacionar, pues, el impe-

${ }_{10}$ Los casos del subjuntivo en que ésta muestra una acepción yusiva poco pueden contra lo que vengo diciendo. Bassols concede demasiada importancia a tales atribuciones imperativas a propósito de algunos ejemplos: Mio Cid: vayádesme, v. 89; fagádes, v. 257, etc., y otros del Romancero. A mi parecer, no son sino una de tantas señales de la indeterminación de funciones y valores de los modos y tiempos verbales del castellano antiguo. De hecho, los ejemplos escasean a partir del siglo XVI, y los pocos que hallamos poseen un neto matiz arcaizante. Resulta, además, que suelen darse después de locuciones imprecativas, y ello es debido al envolvimiento de una elocución indirecta por la que el subjuntivo se sujeta a un verbo regente en primera persona + que: "por vida de", "por amor de": por tu vida (quiero) que digas los versos, Montemayor, Diana, 18r., 26. 
rativo con el subjuntivo, es preciso que partamos de un punto común que los coloque en la misma línea de significación: es decir, la expresión exhortatoria que, por lo menos en principio, enlaza Quiero que limpies tu bolso, Elvira con Elvira, limpia tu bolso. Con todo, ambas construcciones no son idénticas. Hay diferencias que las separan y determinan, de esta manera, el lugar distinto que cada una tiene en el espacio de la gramática. Esto me lleva a discrepar de la suposición de Bello, quien opina que el imperativo es una síntesis elíptica de una construcción más amplia. Al incluirlo dentro del "subjuntivo común", entre las "formas optativas" — si bien con una "inflexión especial"-, pienso que Bello se ve forzado por la necesidad contraída por su concepción de los Modos, a la que tiene que ajustar el imperativo y asignarle un puesto entre ellos por la subordinación que supone - según él- a otra palabra o expresión. De no ser así, no se le oculta que el imperativo establecería una excepción (lo que sería un mal principio para aceptar la validez general de una definición). Bello cree resolverla -y estimo que la pretensión supera a la realidad - imaginando que el imperativo está regido poŕ alguna palabra dominante que lo reduce a la subordinación mediante el subjuntivo. Así - dice-, dí, ven, hablad, escribid son abreviaciones de quiero que digas, deseo que vengas, que habléis, que escribáis. ${ }^{11}$

El primer reparo que pongo a la doctrina de Bello se refiere a los verbos que encabezan estas construcciones. Querer y desear son verbos de voluntad. Verbos que muestran, aquí, el deseo de quien habla. Pero - e insisto en lo dicho - la sola declaración de un deseo no presupone, de suyo, un mandato. Sería menester que otros indicios del contexto lo determinaran (en la medida de que un simple deseo constituyera una orden). Es de suponer que Bello les atribuya este carácter obligatorio, aunque no lo precise convenientemente. Así pues, dí será igual a quiero, deseo, en tanto sean equivalentes a exijo, mando... que digas.

Por otra parte, si la distinción de los Modos está basada en la influencia o régimen que los verbos pueden recibir - lo que compromete, sin duda, a la sintaxis de la frase-, su doctrina se decanta por el lado del imperativo, pues la pretendida similitud se llevaría a cabo -y no exactamente- en el plano semántico, en cuanto señala correspondencias de significado, pero sin afectar a la sintaxis particular de cada construcción. Cuando queremos que alguien diga algo, y el predicado decir + tú está, de hecho, determinado por un verbo o expresión de deseo, ruego o mandato, adopta entonces el subjuntivo, en virtud de formar una proposición complementaria introducida por el conector subordinante que: deseo, te ruego, te mando - que-digas. Ahora bien, si el predicado decir + tú toma - asimismo para expresar una ordenla forma dí, distinta de la fórmula que lo inclina hacia el subjuntivo, sospecho que se debe a que no actúa ningún resorte que implique dependencia alguna. Se da únicamente una coincidencia de significados bajo

11 Bello, Gramática, op. cit., pág. 177. 
construcciones que siguen caminos paralelos $-\mathrm{y}$ no se superponen - a la hora de exponer el proceso imperativo: quiero que digas explicita analíticamente cada uno de los elementos que registran la voluntad del que manda y el objeto del mandato, al tiempo que el imperativo, dí, lo reproduce por otros medios, no precisamente por una "síntesis elíptica" del anterior (y lo prueba también el hecho de que, como es lógico, se conserve el subjuntivo en el caso de ir implícito - por verdadera elipsisel verbo regente: ¡que digas!, ;que lo digas! deseo, te ruego, te mando), sino por "condensación" de dicho proceso en una forma especial y exclusiva que los verbos poseen para expresar directamente un mandato, verificado en un modo particular y definible por sus propios rasgos formales, con repercusiones en la sintaxis de la frase - de una frase siempre independiente y liberada por el estilo directo que emplea el hablante-, como se advierte, p. e., en los pronombres personales complementarios átonos, en posición enclítica en el imperativo, díME, y proclítica en las otras formas del verbo finito, quiero que $M E$ digas. $\mathrm{O}$ en el caso del sujeto, separado por la pausa a manera de vocativo (tú, dí o dí, tú) o con entonación ininterrumpida (quiero que tú digas, quiero que digas tú), respectivamente.

2.3. El imperativo no se mide desde el tiempo del hablante, desde el presente en que formula el mandato, sino que proyecta su temporalidad al momento de la ejecución, que es necesariamente futuro. Esta temporalidad futura nos impide reconocer en el imperativo los valores del "aspecto" al no existir correlación opositiva de término o notérmino de un proceso. Me atengo al criterio que fija esta demarcación entre los muchos que tratan de definir el aspecto verbal. El futuro indica que la acción aún no ha comenzado, y mal podremos andar con distinciones aspectuales en un proceso que todavía no existe. La acción se presenta sólo como prospectiva y virtual. ${ }^{12}$ A la ausencia, en el imperativo, de esta clase de aspecto, el flexional, hay que añadir también

12 C. Hernández, sin embargo, incluye el futuro absoluto entre los tiempos aspectualmente perfectivos (vid., "Sobre el tiempo en el verbo español", cit. ant.).

También F. Marcos Marín (vid., Aproximación a la Gramática Española, Madrid, ed. Cincel, 1974, pág. 189), entre otros, aunque identifica, en el futuro, aspecto y aktionsart. Respecto al imperativo, "Su aspecto -escribe- es perfectivo, pues indica acción terminada. Es realmente el único perfectivo en el futuro, pero esto se debe a que no se trata de un tiempo, sino de un modo, cuya significación propia consiste en ser perfectivo en el futuro. Conviene aclarar que esta perfectividad está en la conciencia del que manda, no en la acción. La acción se indica como mandada, pero el que la manda la piensa hecha." Yo no lo veo así. Sigo pensando que la perfectividad o imperfectividad de la acción ha de venir enmarcada siempre en un proceso, pero objetivado realmente en el tiempo - imposible tratándose del futuro- y no subjetivado mentalmente en la conciencia del que manda, pues, por lo que toca al alcance del imperativo, ni aun la conciencia más presuntuosa imagina los hechos del mandato como ya realizados. Si lo hace, será únicamente en atención al grado de jerarquía reconocido por los interlocutores. 
la del aspecto sintagmático, ya que carece de correspondencia contrastiva entre su forma simple y otra compuesta. ${ }^{13}$

2.3.1. Más allá de su propio sistema, el imperativo se extiende, en el habla, a otras formas del verbo; al presente y al futuro de indicativo, ${ }^{14}$ a causa de las consignificaciones que se desprenden de su condición de tiempo-modo.

El carácter imperfectivo del presente facilita su momentánea acepción conativa: Tú me esperas en el bar y te tomas un café. Coges dinero y compras el pan. Venís a mi casa y me contáis lo ocurrido. ${ }^{15}$ Por medio del presente, el hablante actualiza los hechos que han de seguir

${ }^{13}$ Según la distinción establecida por J. Holt (Études d'aspect, Copenhague, 1943), tan certeramente aplicada al español por $\mathrm{E}$. Alarcos.

14 Contra lo que suele hacerse, no incluyo al infinitivo porque, en realidad, no asume el valor y la función del imperativo. No se produce una metábasis que remueva su entidad gramatical. El fenómeno se explica - en mi opinión- como un mero desvío fonético - $\sin$ más motivos ni repercusiones-, debido a la resistencia que el hablante encuentra en la pronunciación de la - $d$ final (morfema característico del imperativo plural), que pasa a la $-r$ del infinitivo, coincidiendo con otra forma verbal, cuya indiferencia de persona, modo y tiempo ayuda no poco a la consolidación de su empleo. (Esto - me parece- anula los reparos de Martín S. Ruipérez (cf. loc. cit. supra, pág. 93), quien aduce en favor del infinitivo el hecho de que el trueque cancad cantar se da también en zonas donde se conserva la $-d$ aunque sea como 0 . Pero la verdad es que el hablante no se ve arrastrado, en esos otros casos, hacia formas de alguna manera tenidas como paralelas). Testifica nuestra explicación que tal aso se tenga por incorrecto, cuando no lo sería si se tratara de un verdadero préstamo de funciones.

Y lo prueba que en el infinitivo dé cabida solamente al plural, ya que esa nueva función habría de afectar también al singular, pues nadie puede suponer, creo yo, que la variación numérica del sujeto sea la causa de la limitación. La construcción de infinitivo con un sujeto singular sólo es posible con la preposición $A$ : túu, $a$ estudiar; tú, a trabajar. Mas entonces el infinitivo no representa ya al imperativo, sino que viene a ser la parte expresa de una estructura ampliada, con la inclusión de un verbo regente de movimiento, proyectado a través de una construcción exocéntrica de sintagma prepositivo: te mando a estudiar, vé (vas o irás a trabajar). El infinitivo actúa aquí como un elemento complementario. Caso bastante similar al del complemento sustantivo de un verbo sobreentendido: tú, a tu habitación; tú, a tu casa. De hecho, la construcción anterior se resuelve a veces en un sustantivo: tú, a estudiar $\Rightarrow$ tú, al estudio; tú a trabajar

Podría objetarse, quizás, que también acceden al infinitivo aquellas formas imperativas que carecen de la - $d$ final, causa drecta de la transformación. En la prohibición: *No cantar, *No votar, *No fumar, *No asomar la cabeza..., de realización subjumiva, caben dos interpretaciones, según los casos: la analogía con las formas âirmativas, con terminación en $-d$, $y$, a partir de ellas, su acceso al infinitivo, o bien una fómula del tipo Se ruega - no cantar, etc. En los imperativos pronomineles: acercaos *amaRos, sentaos "sentaRos creo que la -R- ejerce una misión antihiática, al tiempo que los equipara formalmente al infinitivo, cuyo uso en lugar del imperativo está tan arraigado en la pronunciación.

15 Para explicar este uso del presente, no hay que descartar tampoco los motivos de naturaleza fonética. Obedece, en más de una ocasión, a la tendencia espontánea hacia la $-s$ final, que imprime su huella en la pronunciación cuando se trata de la segunda persona. 
al mandato, registrándolos en su mente como si la acción ya hubiera sido iniciada y se estuviese realizando. Confía en su autoridad y no duda que será obedecido. De ahí que lo destine sobre todo a personas iguales o inferiores.

Hay un punto en que las Gramáticas no suelen reparar, y creo que es notable su repercusión en la sintaxis. El presente-imperativo no se da -o muy difícilmente- en construcciones independientes y aisladas. Es posible que nos dirijamos a nuestro interlocutor sin previo aviso o señal alguna de nuestra intención, diciendo: Ven a mi despacho, Andrés, pero no Vienes a mi despacho, Andrés, pues el presente indica el resultado o consecuencia de una situación creada antes, de la que participan tanto el hablante como el oyente, y que origina el mandato. Bajo esta perspectiva se explica mejor la actualización del predicado. Así, es de ver que tales construcciones van con frecuencia apoyadas en palabras confirmatorias de dicho resultado: $Y$ ahora, vienes a mi despacho, Andrés, o como término de un proceso de movimiento espiritual o físico: Piensa en lo que te propongo y me das la respuesta, Acércate y lo compruebas tú mismo, o, en definitiva, cualquier determinación del contexto. Tiene lugar, pues, en estructuras de ordinario bimembres, en las que alternan el presente y el imperativo en uno de los extremos, o bien repetidos, de carácter temporal: Cuando regrese tu padre, sales a su encuentro, condicional: Si tienes frío, te pones el abrigo, concesiva: Aunque llueva, riegas el jardín. En una palabra, que signifiquen relación causativa.

En las debidas circunstancias, también el futuro puede expresar un mandato. Pero, ¿qué matices brotan entonces?: ¿suponen un refuerzo o una atenuación del mismo? Las opiniones se han repartido con respuestas afirmativas para uno $\mathrm{u}$ otro término de la pregunta. La mía aboga por el carácter fundamentalmente yusivo. Incluso adquiere mayor fuerza conminatoria y disipa la posible duda o vacilación en quien ha de llevar a cabo el mandato. Así lo advierto en Abrirás la puerta respecto a Abre la puerta. Si declina su rigor hacia el ruego o la súplica, será por otras causas. Las mismas que son capaces de mitigar cualquier imperativo categórico. Tal vez resulten más fáciles, y repercutan más, cuando el mandato compromete a un superior, pues es lógico que pierda entonces su energía desde la base intencional del que da la orden (a no ser que éste se revista momentáneamente de una autoridad que anule la situación real). Todos los ejemplos - muchos- que hemos analizado testifican que el debilitamiento obedece a síntomas externos, que se pueden agrupar en los siguientes: a) fórmulas de cortesía (excepto, claro está, si son introducidas con un sentido irónico): "por favor", "si usted quiere", "si le parece"...: Abrirás la puerta, por favor; Abrirá usted la puerta, si le parece. b) Cualquier palabra o expresión que aclaren el modo particular de entender una frase: así como en Abrirá usted la puerta CON CUIDADO, la advertencia elimina todo atisbo de lisura en la expresión, que pudiera desprenderse del tratamiento respetuoso, aparece, sin embargo, en Abrirá usted la puerta CON FACILI- 
$D A D$. c) El propio significado del verbo, favorecido por la situación contextual: Me comprenderá usted, si le digo...; Me aconsejará qué debo hacer. d) La interrogación cortés: ¿ ¿Me prestará una pluma? Más aún, si surge la acción mitigadora de los verbos morales: ¿Querrá usted prestarme su pluma?, ¿Podrá usted abrir la puerta?

3. Aparte de la forma exclusiva del verbo, corren por nuestra lengua muchas y muy variadas expresiones de mandato. Aunque todas encubren, en el fondo, un predicado imperativo, algunas se presentan con una base no verbal, y han quedado como petrificadas en el habla por efecto de la elipsis. La entonación es el vehículo por excelencia que conduce la voluntad obligatoria del hablante. El tono exclamativo puede equivaler a una voz de mando: jaquí!, jalli!, jadelante!, jarriba!, ¡abajo!, jafuera! = jven aqui!, jven alli!, javanza!, jsube!, jbaja!, jsal!, ¡márchate!, a una recomendación: jatención!, ;cuidado!, jojo! = jatiende!, jcuida!, jmira! Asimismo, hace poco me he referido a la modalidad interrogativa, capaz de producir un mandato o teñirlo de ironía, reconvención o mesura: ¿trabajarás toda la noche?, ¿terminarás de una vez?, ¿echará usted la carta?

El estudio de la expresión imperativa se puede abordar desde ángulos muy distintos. ${ }^{16}$ Pero mi propósito quedó patente al iniciar este trabajo y creo que se ha ido confirmando: el imperativo del verbo. Me limitaré, pues, en lo sucesivo, a analizar aquellas construcciones que se asientan en un núcleo verbal. Y, como ha sido mi norma, evitaré caer en una mera presentación o exposición de los hechos, para detenerme, sobre todo, allí donde la revisión o crítica se hacen más necesarias.

3.1. Para E. Lorenzo, ${ }^{17}$ la construcción elíptica de infinitivo de pretérito, ¡Haberlo dicho! (a veces presentada en forma personal, jque lo hubiera dicho!), está vinculada estrechamente con las perífrasis de deber y tener que - cuyos sentidos de obligación son evidentes-, y cabría interpretarla como una especie de "mandato referido al pasado". Advierte, no obstante, lo paradójico de esta interpretación, ya que un ruego o un mandato van substancialmente proyectados hacia el futuro. Confieso que yo no alcanzo a distinguir ese posible carácter imperativo en referencia al pasado. Hay que tomar la frase, a mi entender, según una de estas dos interpretaciones: 1) En el supuesto de que no se trate de una imposición ajena (pues muy bien puede referirse a algo que el oyente tuviera el deber o la intención de realizar, sin necesidad de que otro se lo hubiese ordenado), y, en tal caso, es imposible reconocer en ella ningún valor imperativo. 2) Si el hablante lo impuso - y aquí radi-

16 Consciente de la falta de un estudio de conjunto, E. Lorenzo analizó algunos pormenores de la cuestión en un sustancioso artículo: "La expresión de ruego y mandato en español", Strenae, 1962, págs. 301-309.

Son también de interés las abundantes y atinadas advertencias acerca de los usos imperativos en la lengua coloquial que leemos en la obra de W. Beinhauer, El español coloquial, Madrid, Gredos.

17 Vid. supra, pág. 306. 


\title{
Gaudioso Giménez Resano
}

ca el problema-, creo que, para que la frase permita apreciar en la actualidad un imperativo anterior, es imprescindible que de alguna manera reproduzca en el momento aquel mandato. $\mathrm{Y}$ no es así. ;Haberlo dicho! no vuelve al mandato en sí, sino sobre el mandato, pues, en verdad, no cabe dar más alcance a su sentido que el que señala las consecuencias que se derivan de su incumplimiento - anotadas muy atinadamente por E. Lorenzo-, por cuyo motivo el hablante se lamenta (;qué lástima que no lo hayas dicho antes!), aconseja "a posteriori" (deberías o tendrías que haberlo dicho), muestra su insolidaridad (jaguántate!, es culpa tuya), reconviene (podrias haberlo dicho).

3.2. En relación con haber y tener, surge un problema que afecta nada menos que a la estructura del imperativo. Bello todavía distingue dos formas:

\author{
Canta (futuro) \\ Habed cantado (ante-futuro)
}

Se limita a decir que el ante-futuro carece de segunda persona singular y a señalar el escasísimo o ningún uso del plural, añadiendo que esta falta queda suplida por el imperativo de tener, construido con el participio adjetivo cuando lo hay. También discrepo del maestro insigne en esta ocasión. Mi punto de vista es otro. Veamos.

Si habed cantado fuera imperativo de cantar, resultaría una forma compuesta. Haber ("habed") habría sufrido entonces el correspondiente vaciamiento de significado, o gramaticalización, para pasar a funcionar como un mero exponente auxiliar de la composición de la forma (habed + cantado lo mismo que habéis + cantado, habiais + cantado o habréis + cantado). La sustitución por tened cantado exige que "haber" conserve sus propiedades semánticas, $y$, en consecuencia, no realice el papel de auxiliar, porque tener —con significación viva en cualquier construcción - no puede formar tiempos compuestos. Aparte de relegarse como un rasgo dialectal del gallego y del asturiano, tener + participio se diferencia de haber + participio. Mientras la segunda construcción sumerge la acción en el fluir del tiempo, la primera la sitúa en el límite del tiempo; la muestra perfectiva, totalizada, como un hecho consumado que está más cerca del compromiso y la responsabilidad del sujeto. Si las hacemos equivalentes, en lo semántico y en lo sintáctico, se infiere que habed cantado no corresponde a la forma compuesta del imperativo de cantar, sino al imperativo de haber, ligado aún a su plenitud semántica y suplantado —al ir despojándose de ella - poco a poco por tener bajo los requisitos de la concordancia (Habed leído el libro / Tened leído el libro, Habed leída la carta / tened leída la carta, Habed leído los libros / Tened leídos los libros, Habed leídas las cartas / Tened leídas las cartas). El ejemplo que aduce Bello: "En amaneciendo, id al mercado, y para cuando yo vuelva, habedme aderezado la comida", dice muy poco en contra, pues pertenece a la lengua clásica, en que aún no se había llegado a una total delimitación de los usos entre haber y tener. Hay que 
añadir, además, que la concordancia continuaba con sus viejas vacilaciones. ${ }^{18}$

3.3. En el habla, y mediante los recursos pertinentes, el gerundio puede tomar un valor imperativo indiscutible: ;Andando!, como voz de mando dirigida a la tropa, o jMarchando esos cafés!, en boca de quien solicita perentoriamente un servicio, etc. El gerundio constituye la parte expresa de una construcción elíptica. Junto al significado de acción en curso que corrobora positivamente la orden, los matices o significaciones accesorias vendrán determinados por los elementos integrantes de la perífrasis. Las diferencias entre un verbo auxiliar de estado y otro de movimiento se dejan sentir también en esta modalidad imperativa. Estar + gerundio ( $Y$ Ya estáis andando!, iYa estás preparando los cafés!, ;Ya te estás callando!) compromete al oyente con una orden tajante, enérgica, y la fija en el punto de su inicio como un hecho de realización segura, pero sin hacer referencia a ningún otro proceso temporal. Ir (o cualquier verbo de movimiento) + gerundio marca una relación al tiempo del desarrollo de otra acción verbal, como continuación de un proceso causativo o complementario, que dispone, más o menos imperativamente, el ánimo del interlocutor: Mientras me afeito, ve preparando el desayuno.

Por otro lado, frases del tipo: Dale que dale, Corre que corre, $\mathrm{Ca}$ vila que te cavila (o en futuro, Cavila que te cavilarás) han recibido el calificativo de "imperativo gerundial". ${ }^{19}$ Efectivamente, en cualquier ejem-

18 Queda, por otra parte, una nueva cuestión relacionada también con "haber": la forma hé (sobre todo en combinaciones adverbiales, complementos de lugar y complementos acusativos, hélo, hé aquí, hé allí). Bello la considera -como era normal en la época clásica- un imperativo irregular de haber. Tanto es así, que desarrolló paralelamente un plural héis, atestiguado en Timoneda y Lope, o el vulgar "hés", empleado por J. del Encina y Salazar (vid. J. Corominas, Diccionario Cr. Et. de la L. C.). Aunque el problema sigue sin una solución satisfactoria, hoy se ha desechado este origen casi por completo. R. J. Cuervo no halla ninguna conexión con haber ni en el sentido ni en la forma, a pesar de que la crítica de $\mathbf{K}$. Pietsch (The Spanish particle hé, Chicago, 1904) no encontrase razones de historia, fonética o semasiología que se opongan a que sea imperativo de haber. Pienso asimismo que resulta muy difícil percibir un contenido imperativo relacionado con el significado de ten aquí, aun teniendo en cuenta su desgaste y cambio semántico, que también necesitaría comprobación. Fuera de haber, tampoco la creo derivada de 'fe', según la interpretación de Díez, es decir como modificación de 've' (imperativo de $v e r$, ya que me resisto, con Ascoli, a admitir aquí el paso de $v=f$. Ni de la forma "afe" (a fe $A D$ FDDEM), que, tomada en principio como juramento aseverativo, fuese a parar en interjección denotativa de decisión o intimación. Por todo, me parece mucho más justa la etimología propuesta por Menéndez Pidal - recogida por Corominas como más acertada- que la emparenta con la voz presentativa árabe "hâ" (pron. vulgar "hê"). "Fe" y "afe" aparecen ya en el $C$. de $M$. Cid. Y mucho más frecuente con la grafía baspirada, a partir del s. XII (Auto de los Reyer Magos, Berceo, Alexandre, J. Ruiz, Romancero, etc.). La misma aspiración de la $h_{l}$ - dificulta aún más la procedencia de HABERE (vi. Corominas, Diccionario).

19 Vid. L. Spitzer, "Uber den Imperativ" (Aufsätze zur romanischen Syntax und Stilistik, Halle, M. Niemeyer, 1918). 
plo de éstos cabe la sustitución por el gerundio correspondiente. Pero, ¿hasta qué punto rozan el imperativo? Son fórmulas incrustadas en la narración indirecta, con un sentido muy alejado de la expresión de mandato. Fórmulas que no van más allá de la forma imperativa. Y aun ésta es difícil de reconocer, porque tales construcciones suelen rechazar las formas de imperativo menos confundibles, como son las irregulares, y buscan formas concurrentes con la tercera persona del presente, o muy próximas, debido al grado de referencia neutra e impersonal. De hecho, se emplean lo mismo con sujetos de $1^{\mathrm{a}}$ persona que de $2^{\mathrm{a}}$ o $3^{\mathrm{a}}$. Así pues, la denominación "imperativo gerundial" la juzgo vaga, imprecisa, por impropiedad de la designación.

F. Krüger, en un jugoso comentario, trata de ordenar y clarificar lo que encuentra oscuro en el trabajo de Spitzer (vid. $R F E$, IX, 1922, págs. 182-193). 